\title{
Report of the Voucher and Accreditation Evaluation Project
} Meeting

Reproductive Health Vouchers Evaluation Team

Population Council

Follow this and additional works at: https://knowledgecommons.popcouncil.org/departments_sbsr-rh

Part of the Demography, Population, and Ecology Commons, Health Policy Commons, International Public Health Commons, and the Women's Health Commons How does access to this work benefit you? Let us know!

\section{Recommended Citation}

Reproductive Health Vouchers Evaluation Team and Population Council. 2012. "Report of the Voucher and Accreditation Evaluation Project Meeting," November 2011, Mombasa, Kenya. Nairobi: Population Council. 


\section{Report of the Voucher and Accreditation Evaluation Project Meeting}

November 7 - 9th, 2011 | Mombasa, Kenya 


\section{Are we moving toward a new community of practice?}

The technical advisory meeting brought together, for the first time, 45 participants from the five country programs being evaluated through the Reproductive Health Voucher and Accreditation (V\&A) project, which is implemented by the Population Council with financial support from the Bill and Melinda Gates Foundation (BMGF). The country program representatives came from Ministries of Health, private sector management firms, NGOs and parastatal organizations. In addition, representatives from BMGF, KfW, DFID, USAID, WHO, the Susan T. Buffet Foundation, the World Bank, Marie Stopes International (MSI), Population Services International (PSI) and the Population Council participated in the meeting.

This group met for the first time as a newly emerging "voucher community" to learn from the successes and challenges faced in this early growth phase of emerging V\&A programs that deliver maternal and reproductive health services. For the first two days, participants reviewed each V\&A program's functions and design. Program managers presented key features, service trends, expected next steps and took questions from the group. There was a stimulating exchange of ideas with plenty of frank discussion.

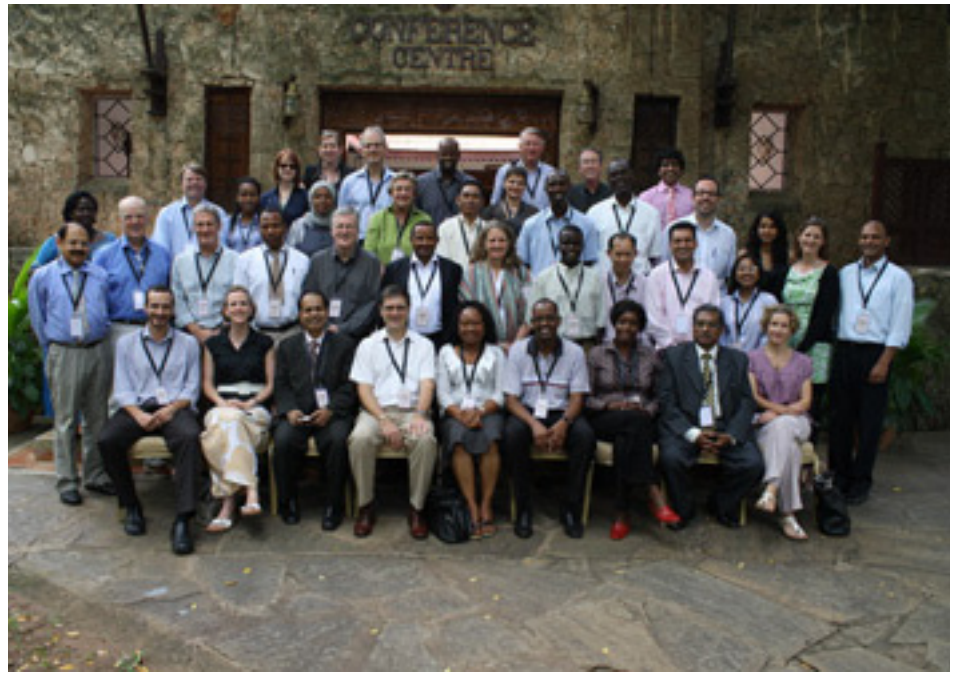

Participants from the Voucher and Accreditation Evaluation Project Meeting in Mombasa.
The group agreed that annual meetings with similar levels of interaction would be useful, supplemented with regular online dialogue. The group was keen to continue to exchange ideas remotely and were interested in meeting again in person if the opportunity arose. When the idea of a community of practice was raised, there was general agreement that continued exchange is important but there were differences of opinion on how to best to leverage it. There was also a question whether to create a narrowly focused community of practice (CoP) specifically for maternal and reproductive health $V \& A$ programs, or to join a larger existing healthcare finance CoP.

For the immediate future, we will encourage strategic engagement with the wider healthcare finance community. In Cambodia for instance, a new healthcare finance CoP is taking shape and the Population Council through the $\mathrm{RH}$ Vouchers project is involved in early discussions and planning. In the Africa region, the PBF community of practice has an active online exchange and adding voucher voices could strengthen the discourse among implementers. However, there will continue to be opportunities that will draw together voucher implementers on specific issues as was done in the April 2011 Nairobi MIS workshop. 


\section{Metrics for monitoring}

Participants also had lively discussions on the role of metrics and which type of indicators should be prioritized for monitoring and evaluating V\&A performance. For example, presentation of a table summarizing the proportion of births supported by vouchers among the lowest $40 \%$ wealth quintiles for the programs in Bangladesh, Kenya and Uganda showed that these pilot programs operating in a limited number of districts have already achieved significant coverage, ranging from $5 \%$ to $11 \%$ of all births to the bottom $40 \%$ of households in their respective countries.

Reporting client numbers is a fairly easy indicator to measure. It was clear that significant work remains to improve the development and use of other metrics that enable meaningful comparisons of programs. For instance, there is not yet a standard metric between countries to measure a key counterfactual indicator of use (e.g. the proportion of service users who would not have used the service in the absence of the voucher) or to rank voucher facilities on a common indicator of quality of care. The $\mathrm{RH}$ Vouchers project has taken steps to define some common performance indicators but there is a lot of work remaining to pilot and validate these measures over the next 12 months.

When asked to rank indicator preferences, the group identified cost indicators as the most desirable group of metrics for decision making. Yet, to date there are very few financial indicators. Obtaining valid and reliable costing data for service delivery financing is always challenging; however, the group agreed that the development of a few time-specific ratios from voucher distribution and claims reimbursement data could provide meaningful indicators of program performance. For example, the financial value of the ratio of rejected-topaid claims, the ratio of average costs for c-sections to normal deliveries, or the management costs to service delivery ratio are all figures that could be generated and reported by programs with little additional effort, and which would give managers, governments and donors an important insight into the financial sustainability of a program.

It also became apparent that verification of performance indicators will become more important if cross-program comparisons are to be made. Service delivery verification requires a system to routinely conduct spot checks on facility quality, interview sampled clients at home about their service experience and their socio-economic status, and review monthly utilization trends in program databases. Such performance measures would be immediately useful for program management but, as of yet, there is no standard methods for generating these figures across countries.

In addition to standardizing the collection of performance and financing metrics, who would use such data and how to present the indicators were discussed extensively. Each Voucher Management Agency (VMA) needs routine feedback on program processes if it is to improve its performance. Other stakeholders - the government steward, donors, and external evaluation units - can also use the performance data to improve the policy environment and evidence base for pro-poor social protection programs such as V\&A programs. 
To facilitate access to such metrics, the group considered the utility of developing a webbased management tool that could both be a data entry platform and display indicators in 'real time' for a much improved understanding of program performance. Such a tool would require that data entry take place either at district or facility level and users could have different levels of access depending on their need for and use of the data. Meeting participants saw value in developing such a system for collecting and visualizing common, comparative indicators.

\section{Technical advisory committee (TAC)}

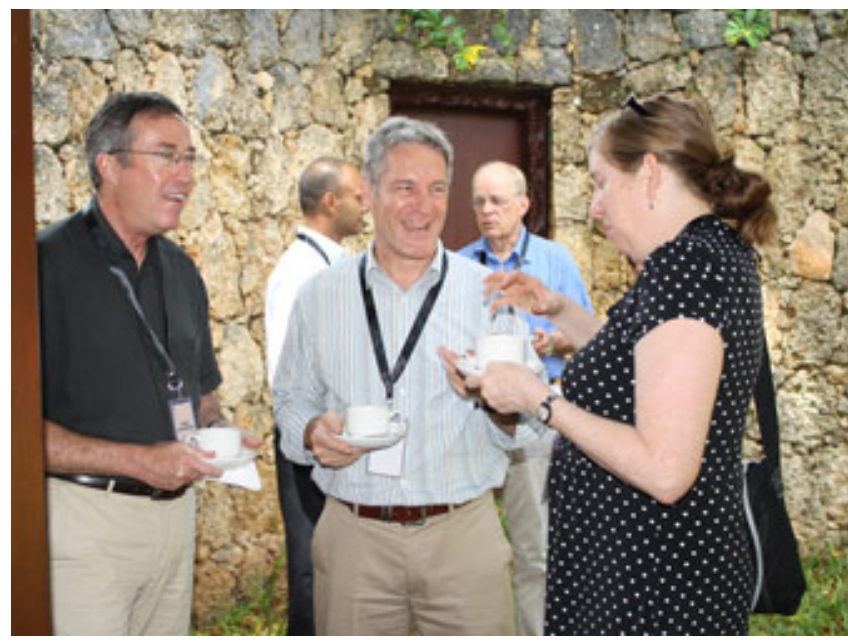

Participants from the Voucher and Accreditation Evaluation Project Meeting in Mombasa.
The original purpose of an annual meeting was to seek input from the project's technical advisory committee (TAC); this was the third TAC meeting. The TAC members met separately from the rest of the participants on the second day to review progress with the RH Vouchers evaluation's activities and to discuss key points for the next phase of the project. This next phase is particularly critical; the endline surveys for several countries begin in mid-2012 and several ancillary studies (e.g. facility expenditures, client follow-up) are being finalized in the coming months. The TAC identified the following priorities for the remainder of the project period:

\section{UTILIZATION TRENDS AT POPULATION AND FACILITY LEVELS FOR VOUCHER-} SUPPORTED SERVICES. The TAC recognized that a key measurement challenge is to identify the proportion of new service users, defined as those who would not have used the services available through the health system if they had not benefited from receiving or purchasing a voucher. The TAC also noted that, for FP services, although use of a contraceptive method is an important endpoint indicator, discontinuation rates would also be a meaningful indicator for population-level impact evaluation. Moreover, for the Tanzania program, there is interest in determining the numbers of households that remain in the Community Health Fund (CHF) after the first free year's membership expires and regular insurance payments need to be made.

2. QUALITY OF FACILITY SERVICES. The TAC emphasized the importance of documenting how voucher revenue is re-invested into the health system as a measure of quality improvement. Defining quality using the Donabedian framework of structure, process and outcomes, investment in facility improvements represents one mechanism through which quality of care can be improved. Given the findings emerging from the project's analysis of revenue investment in Kenya, TAC members suggested that the preparation of guidelines 
for revenue investment associated with $V \& A$ programmes would be a useful product. The TAC also reminded the project team to systematically document and measure whether competition existed between providers and whether it acted as a mechanism for stimulating quality improvement, both during facility accreditation and when clients express preferences for specific facilities by selecting some and not others.

\section{CLIENT PREFERENCES. The TAC}

discussed the value of measuring the role of vouchers in changing client preferences and capturing data on their experiences at both voucher and nonvoucher facilities. The TAC again mentioned the importance of documenting competition as a motivating and incentivizing factor.

\section{OPTIMIZING MIS STRUCTURES} AND STANDARDIZING INDICATORS. Now that the baseline MIS surveys are completed, the TAC recommended developing standards for a generic MIS for V\&A programs that could be used to guide their launch and/or subsequent expansion. The TAC suggested that a standard template for reporting performance across countries would be helpful; developing comparable metrics would therefore also be a priority for the project.

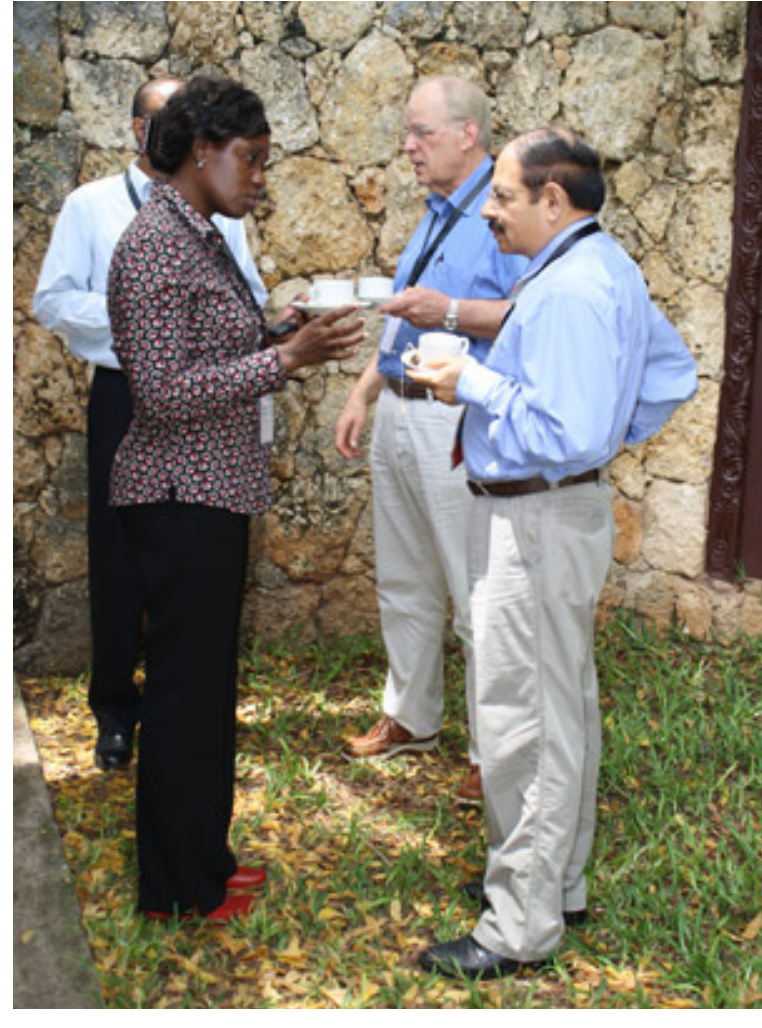

Participants from the Voucher and Accreditation Evaluation Project Meeting in Mombasa.

\section{COMMUNICATIONS, INCLUDING A CLEARER RESEARCH AGENDA STATEMENT.}

The TAC appreciated the preliminary reports produced to date and the presentation of the timeline for the remainder of the project. Members also requested a clearer statement of the forthcoming research priorities for the project. Identifying and prioritizing a research and analysis agenda is all the more important given the huge amount of information being generated by the project. The TAC recommended undertaking a larger number of insightful analyses and more syntheses across the datasets. TAC members were keen to see the project developing and disseminating educational materials, and creating policy briefs and other materials that contribute new insights on program functioning.

\section{COSTS ASSOCIATED WITH VOUCHER AND ACCREDITATION PROGRAMS. The}

TAC suggested greater emphasis on exploring the cost drivers in health systems so that these could be addressed through voucher programs. Interest was also expressed in determining the cost-effectiveness ratios for voucher-supported services in comparison with services delivered through regular health systems using input-based financing. The TAC was also interested to see more analysis of cost ratios to gauge performance. 